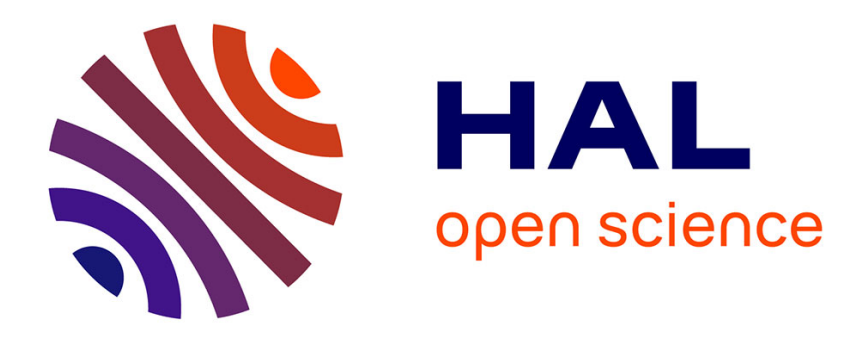

\title{
Applications of Laser Techniques to Field Ion Microscopy
}

T. Tsong

\section{To cite this version:}

T. Tsong. Applications of Laser Techniques to Field Ion Microscopy. Journal de Physique IV Proceedings, 1996, 06 (C5), pp.C5-15-C5-24. 10.1051/jp4:1996502 . jpa-00254381

\section{HAL Id: jpa-00254381 https://hal.science/jpa-00254381}

Submitted on 1 Jan 1996

HAL is a multi-disciplinary open access archive for the deposit and dissemination of scientific research documents, whether they are published or not. The documents may come from teaching and research institutions in France or abroad, or from public or private research centers.
L'archive ouverte pluridisciplinaire HAL, est destinée au dépôt et à la diffusion de documents scientifiques de niveau recherche, publiés ou non, émanant des établissements d'enseignement et de recherche français ou étrangers, des laboratoires publics ou privés. 


\title{
Applications of Laser Techniques to Field Ion Microscopy
}

\author{
T.T. Tsong \\ Institute of Physics, Academia Sinica, Taipei, Taiwan, Republic of China
}

\begin{abstract}
Laser light has been used in field ion microscopy for mainly three purposes. First, for studying photon stimulated effects on field ionization and field desorption. Second, pico-second pulsed-laser technique has been used in time-of-flight atomprobe operation with some advantages. Beside being able to field evaporate semiconductors and to improve the mass and energy resolution; many interesting effects have been found. Third, laser light has been use for heating the very small part of the tip apex either in continuous time of in ns puises. In the latter case, the effects of rapid heating and quenching of material surfaces, the atomic motion and surface reconstruction produced by the heating of ns laser pulses can be studied. Our studies in field ion emission, ion physics and surface science are reviewed.
\end{abstract}

\section{INTRODUCTION}

During the early stage of development of lasers in the 1960's, Professor Müller recognized the importance of applying this new technique to field emission research in two aspects [1]. First, the fast, high power laser pulses could be used for studying the rapid heating and quenching effects of material surfaces. For this purpose, he managed to purchase a high power Q-spoiled laser for an exploratory study with Nishikawa and MCLane, Jr. Unfortunately, the laser power was very difficult to control during this early period, thus they did not continue their work after some unsuccessful experimental trials. Müller also recognized that $\mathrm{CW}$ lasers of lesser power could be used for heating the tip. The advantage was to heat the tip apex locally. As I have always been interested in studying field ion emission and other surface phenomena, when Müller and I wrote the 1969 book on field ion microscopy, I emphasized that the intensive laser light could be used to study photo-excitations at the emitter surface, and also the effect to field ionization and field desorption. Since the Q-spoiled laser purchased by Müller was too unstable and too difficult to handle, this type of research was not pursued.

In September 1975, I went to the laboratory of Professor Block for my sabbatical. During the last several years prior to this visit, one of my research interests was field ion emission and field adsorption phenomena. At that time, photo-emission was a hotly pursued subject in surface science, and photon-stimulated field emission was also pursued. It was natural for me to ask Professor Block to purchase a new, much more stable laser unit for me to study photo-excitation effects in field ion emission. He was not sure first but then went along with my idea. In a new environment, purchasing of components for building a simple FIM chamber took me over six months. By the time the system was ready for experiment, only less than two months was left of my sabbatical. It was still very expensive to purchase a laser unit at that time. Professor Block was able to persuade a laser company to rent us a unit for the initial testing. Within a month or so, we have succeeded in observing an enhancement effect in the field ion current from an 
aluminum oxide tip by the irradiation of laser pulses, but no such enhancement was found from a tungsten surface [2a]. Photo-enhanced field ionization and field desorption was later explored with synchrotron radiation with Jaenicke et. al. where desorption yield was measured as a function of the photon energy [2b].

During late 1970's, time-of-flight atom-probe technique was in active development. Two difficulties encountered during that period were the poor mass resolution and the inability to field evaporate semiconductor surfaces using ns high voltage (HV) pulses. Since during my study of photon excitation in field ion emission, I already observed very well controlled field evaporation of both metal and metal oxide surfaces by the action of laser pulses, and I was also expecting a much improve mass resolution because of the much smaller ion energy spread by photon excitation, either by heating or quantum effect, than HV pulse field evaporation, I proposed to develop a pulsed-laser ToF atom-probe [3]. Unfortunately, the lack of support from the community prevented me from finding the needed funds to develop a pulsed-laser atom-probe. The development came when I visited Sandia Laboratory in the summer of 1980 . Kellogg and I succeeded in developing a pulsed-laser imaging atom-probe using a simple nitrogen laser [4]. The possibility of field evaporating the silicon emitter surface was demonstrated. The resolution part was later demonstrated when a linear type ToF pulsed-laser atom-probe was developed at Penn State [5]. This system, after several years of improvement (Fig. 1), can now achieve \pm 1 to 2 parts in $10^{5}$ accuracy in the determination of ion masses and ion energies after a careful calibration. Here I will describe a few of our studies done with pulsed-laser techniques.

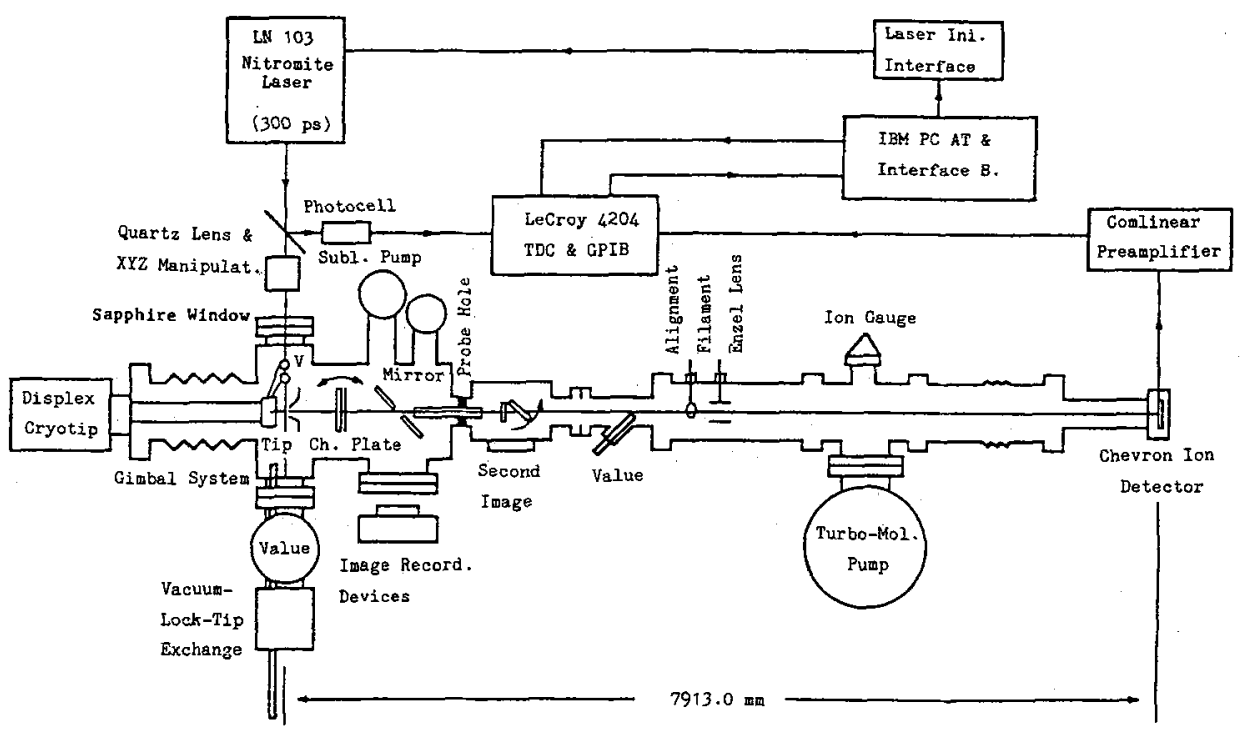

Fig. 1. A pulsed-laser ToF atom-probe FIM built by the author's group.

\section{PHOTON-ENHANCED FIELD IONIZATION}

Field ionization can be enhanced by the irradiation of laser light. Argon field ion current near the threshold field of field ionization from an aluminum oxide tip was found to increase by a factor of about five when the tip was irradiated with $4.16 \mathrm{eV}$ photons from a 
laser of pulse width $2 \mu \mathrm{s}$ width at a repetition rate of $25 \mathrm{~Hz}$, or a duty cycle of only $0.005 \%$ [2]. No such enhancement was found when a tungsten tip was used. Fig. 2(c)-(e) shows three possible mechanisms of photon-enhanced field ionization. As photon energy used is too small to excite $\mathrm{Ar}$ atoms from the ground state to the first excited state, the enhancement has to come from a direct electronic transition between the ground state of the gas atom to a vacant state in the conduction band of the surface as can be expected from the Fermi golden rule (Fig. 2(d)). It is also possible that a vacant state is created in the valence band which is then filled by the atomic electron as shown in Fig. 2(e). The lack of enhancement from a metal surface is due to a rapid reneutralization of the photo-ionized atom by a conduction band state electron as seen in Fig. 2(b).

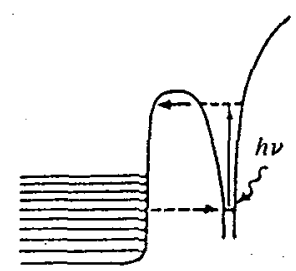

(a)

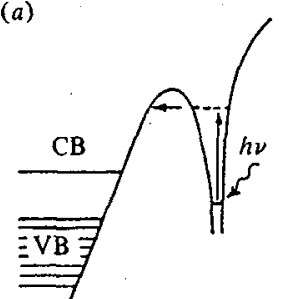

(c)

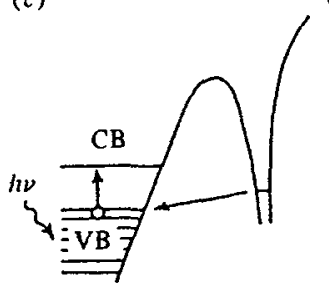

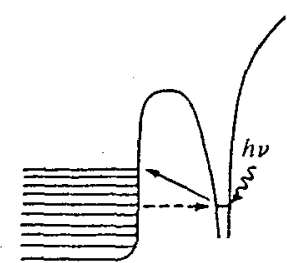

(b)

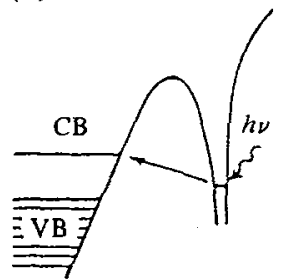

(d)

(e)

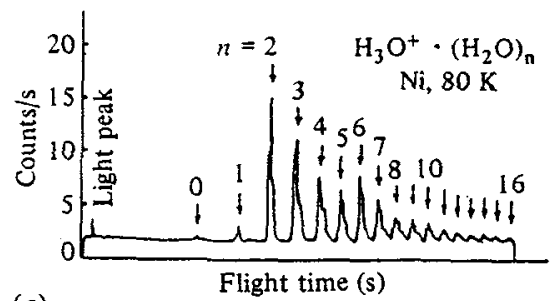

(a)

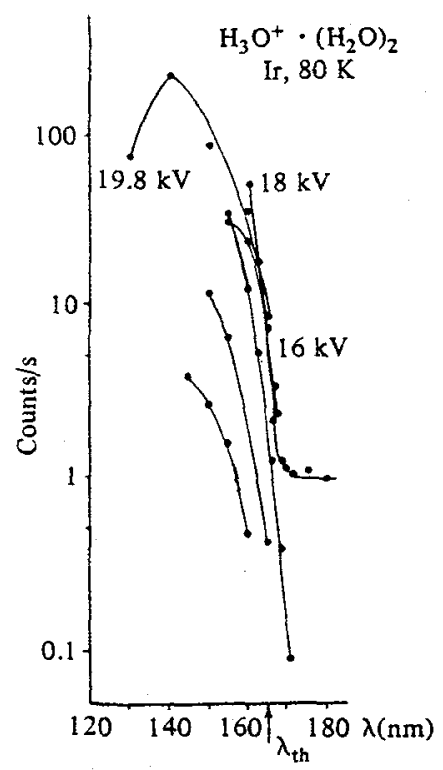

(b)

Fig. 2. (a) and (b) show two possible mechanisms for photon-enhanced field ionization (PEFI) from a metal surface. (c) to (e) show possible mechanisms of PEFI from a semiconductor surface.

Fig. 3. (a) A ToF spectrum in photon stimulated field desorption of water. (b) threshold photon wavelength in photon stimulated field desorption of water. 


\section{PHOTON ENHANCED FIELD DESORPTION}

Field desorption can be enhanced by photon-excitation by either a thermal effect or a quantum effect. Intense laser light can easily excite phonons and heat up the emitter surface. Field desorption can be enhanced by a thermal activation effect. in the case of metal emitters, thermal enhanced field evaporation or desorption can result in formation of a high energy tail in ion energy distribution. The tail is very small unless the laser power is very intense. For silicon, the high energy tail is very pronounced even when the laser intensity if barely sufficient to field evaporate surface atoms. This indicates that the mechanisms similar to those shown in Fig. 2(d) and (e) are responsible for the ionization process in photon-enhanced field evaporation.

In a study of photon-enhanced field desorption using synchrotron radiation, a threshold in photon energy is found for field desorption of water molecules from different metal tips as shown in Fig. 3 [2]. This threshold energy is found to be $7.5 \pm 0.5 \mathrm{eV}$ which agrees with the appearance energy $(I-\phi)$ of water in field ionization and field desorption measurements. In this experiment, the tip is cooled down to $78 \mathrm{~K}$. This threshold value is found to be independent of tip material. Presumably the tip surface is covered with a thick layer of ice, therefore photon stimulated field desorption of water occurs really from the surface of ice. The fact that the threshold photon energy agrees with the appearance energy in field ionization indicates that the photons supply the energy which is generally supplied by the applied field, or eFz, in field ionization. Or the mechanism should be that represented by Fig. 2 (d). If laser is well focused to the tip, the power can be made so strong that ions are ejected from the surface with a kinetic energy exceeding $300 \cdot \mathrm{eV}$ regardless of the tip material (Fig. 4). It is not yet clear what mechanism is responsible for the ejection of these high energy ions, neither is there a detailed study of this interesting physical process at the present time. There are obviously still many interesting physics in photon stimulated field ion emission waiting to be studied.
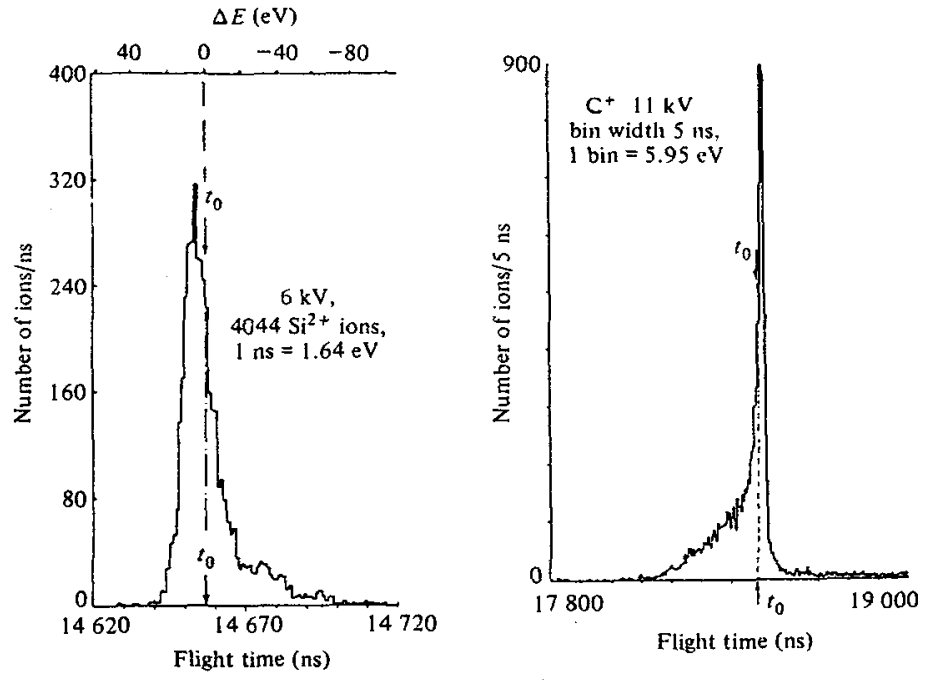

Fig. 4. (a) Even when the laser intensity if barely able to field evaporate $\mathrm{Si}, \mathrm{Si}^{2+}$ ions show kinetic energy in excess of the critical ion energy deficit by over $20 \mathrm{eV}$. (b) If the laser intensity is very high, the excess energy can reach $300 \mathrm{eV}$. 


\section{CLUSTER ION FORMATION}

A subject of considerable interest is the stability of cluster ions, how this is related to the atomic size and charge state, known as magic numbers and critical numbers in Coulomb explosion. In pulsed-laser field evaporation of metals, cluster ions can be formed but the size is very small even when the laser power is increased to the extend that the tip apex will no longer blunt by further field evaporation, or a steady cusp shape is reached by continuous flow of atoms by field gradient and laser heating. An extremely interesting observation comes from Mo. Low temperature field evaporation of refractory metals produces usually highly charged ions. For Mo, the charge state is $\mathrm{Mo}^{3+}$ with a small fraction of $\mathrm{Mo}^{2+}$. In pulsed-laser stimulated field evaporation, as the laser power is increased gradually, the charge state shifts gradually to $2+$ first and suddenly $\mathrm{MO}_{2}{ }^{2+}$ appears without formation of $\mathrm{Mo}^{+}[6]$. The detection of this ion species cannot be done with a mass spectrometer of modest resolution since these two ion species have the same mass-to-charge ratios. Fortunately there are seven isotopes of $\mathrm{Mo}$. For $\mathrm{Mo}^{+}$, there should be seven mass lines separated by $1 \mathrm{mu}$. For $\mathrm{Mo}_{2}{ }^{2+}$, because of isotope mixing, there should be 12 mass lines separated by $1 / 2 \mathrm{mu}$. The observed mass lines shown in Fig. 5 agree with the calculated intensity distribution of $\mathrm{Mo}_{2}{ }^{2+}$ from the isotope abundance of $\mathrm{Mo}$. We conclude that there are very few $\mathrm{Mo}^{+}$ions if they exist at all. The stability of these 2+ cluster ions is amply demonstrated by the sharpness of these mass lines. We estimate the activation energy needed to dissociate this ion is greater than $1.2 \mathrm{eV}$. Before this observation, it was assumed that such ions are unstable because of "Coulomb explosion" of the two positive charges. Obviously such simple argument cannot be correct since these two positive charges are shielded by the electronic charges inside the ion.

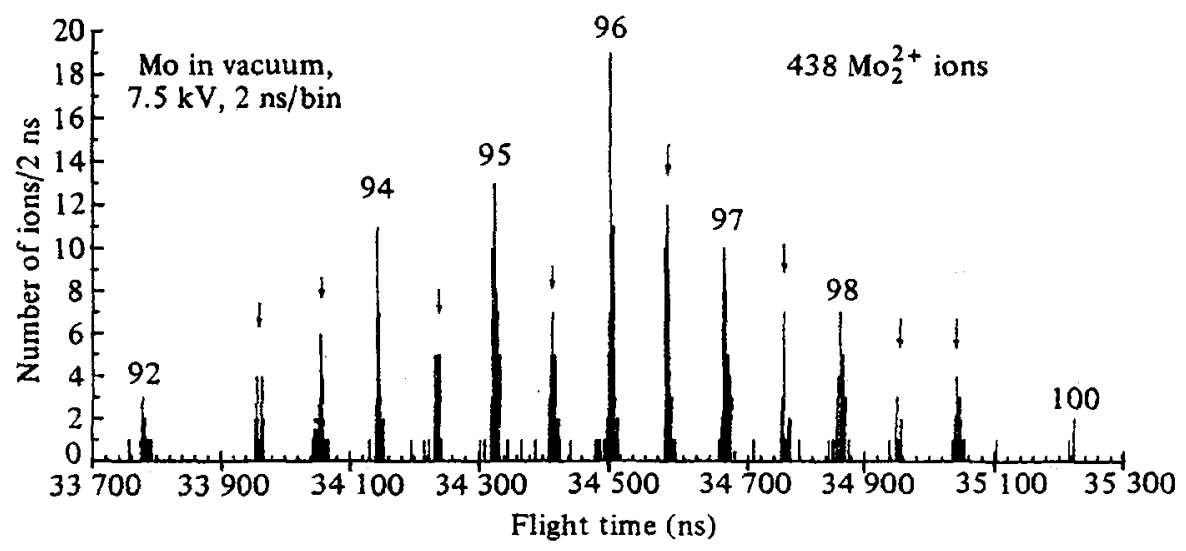

Fig. 5. When the tip is heated above $1000 \mathrm{~K}$, a new ion species, $\mathrm{Mo}_{2}{ }^{2+}$, is formed in photon stimulated field evaporation of Mo. The mass line distribution agrees within statistical errors with that expected from an isotope mixing. 

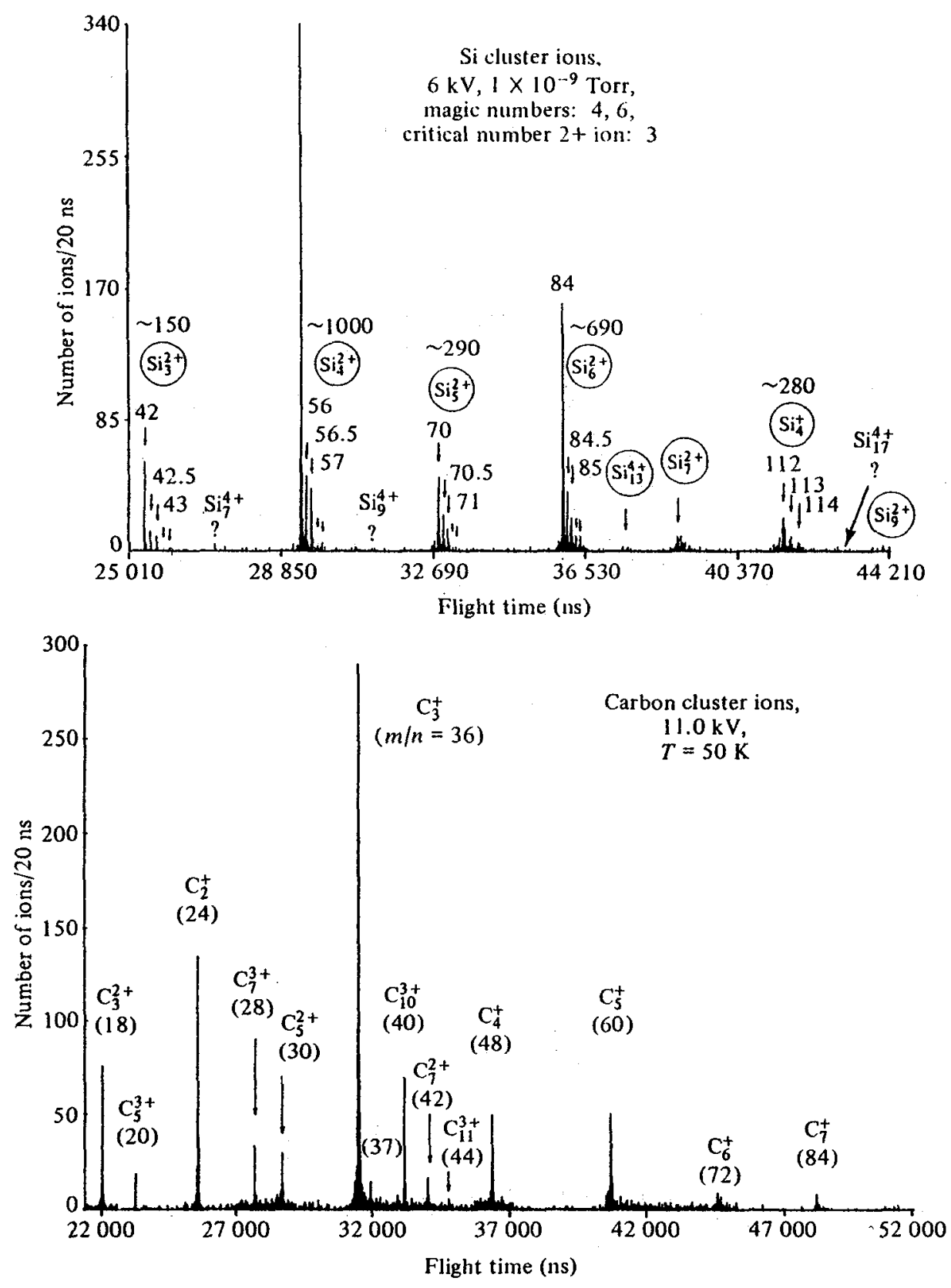

Fig. 6. Mass spectra of $\mathrm{Si}$ and $\mathrm{C}$ in photon stimulated field evaporation of silicon and graphite using intense laser beam irradiation. 
Pulsed laser stimulated field evaporation of silicon produces great abundance of cluster ions if the laser power is sufficiently high [7]. Many of these cluster ions are doubly charged. The line intensity also shows a systematic variation. All the intensities of even size cluster ions are greater than those of odd size cluster ions of comparable size. Also, $\mathrm{Si}_{4}{ }^{2+}$ and $\mathrm{Si}_{6}{ }^{2+}$ show exceptionally large intensities. Thus 4 and 6 are magic numbers. Unfortunately, the largest cluster ions one can obtain with this technique is about 10 because of the very small tip size. Nevertheless, this study preceded and stimulated other successful studies of magic numbers of silicon clusters using laser ablation [8]. Theoretical calculations show that while $S i$ and $C$ are both covalent bond materials of valance 4 , their clusters show a very different stability behavior. For $\mathrm{Si}$, clusters of even atom numbers are more stable than clusters of odd atom numbers whereas for $C$, this is reversed. This theoretical result [9] has been confirmed with our pulsed laser field evaporation experiment [10]. For carbon, all the odd atom number cluster ions have greater intensities compared to even atom number cluster ions of comparable size as shown in Fig. 6.

\section{FIELD DISSOCIATION OF COMPOUND IONS}

One of the most interesting findings of the pulsed-laser atom-probe is field dissociation of ${ }^{4} \mathrm{HeRh}^{2+}$ ions [11]. In pulsed-laser field evaporation of $\mathrm{Rh}$ in the presence of helium gas, the mass spectrum consists of a mass line of $\mathrm{HeRh}^{2+}$ and a line of $\mathrm{Rh}^{2+}$ as shown in Fig. $7(a)$. Whereas the former is a sharp single peak line, the latter consists of a well separated secondary peak. The secondary peak arises from $\mathrm{Rh}^{2+}$ ions of slightly lesser energy, or they are formed at a distance further removed from the tip surface. Our theoretical model is shown in Fig. 8. A field adsorbed He field evaporates together with a $\mathrm{Rh}$ atom to form a HeRh${ }^{2+}$ ion. The ionization energy of $\mathrm{He}, 24.56 \mathrm{eV}$, is considerably larger than the second ionization energy of Rh atom which is $18.1 \mathrm{eV}$. Therefore in this ion, $\mathrm{He}$ is bound to the $\mathrm{Rh}^{2+}$ ion by a polarization force. In a field of a few VIA, if the ion lines up in the direction of the field, i.e. if the vector pointing from the He to the Rh lines up with the field, $\mathrm{HeRh}^{2+}$ can dissociate into a neutral $\mathrm{He}$ atom and $\mathrm{a} \mathrm{Rh}^{2+}$ ion. If the direction is anti-parallel, dissociation cannot occur. Of course, when a HeRh ${ }^{2+}$ is desorbed from the emitter surface, it rotates and vibrates just like any other diatomic molecule or ion. Since when it is desorbed, it is lined up anti-parallel to the field, dissociation cannot occur. Dissociation can occur only after it rotates by nearly $180^{\circ}$ in a spatial zone far removed from the tip surface. From the energy separation to the main peak and the width of the secondary $\mathrm{Rh}^{2+}$ peak, we obtain the dissociation time, or the rotation time by $180^{\circ}$ of this compound ion in the field of about $4.5 \mathrm{~V} / \AA$ to be $790 \pm 21 \mathrm{fs}$.

This field dissociation exhibits a very pronounced isotope effect. When ${ }^{4} \mathrm{He}$ is replaced with ${ }^{3} \mathrm{He}$, field dissociation ceases to occur as seen in Fig. 7 (b). This isotope effect can be understood from the Schrödinger equation governing the relative motion of $\mathrm{He}$ and $\mathrm{Rh}^{2+}$ in the applied field. It arises from a center of mass transformation. A more detailed study resolves the secondary $\mathrm{Rh}^{2+}$ line into two peaks. They are produced by the vibration motion of the compound ion. A fractal behavior in field dissociation can be expected. This study of ours provides deep insight for understanding field dissociation effect in unprecedented detail. 


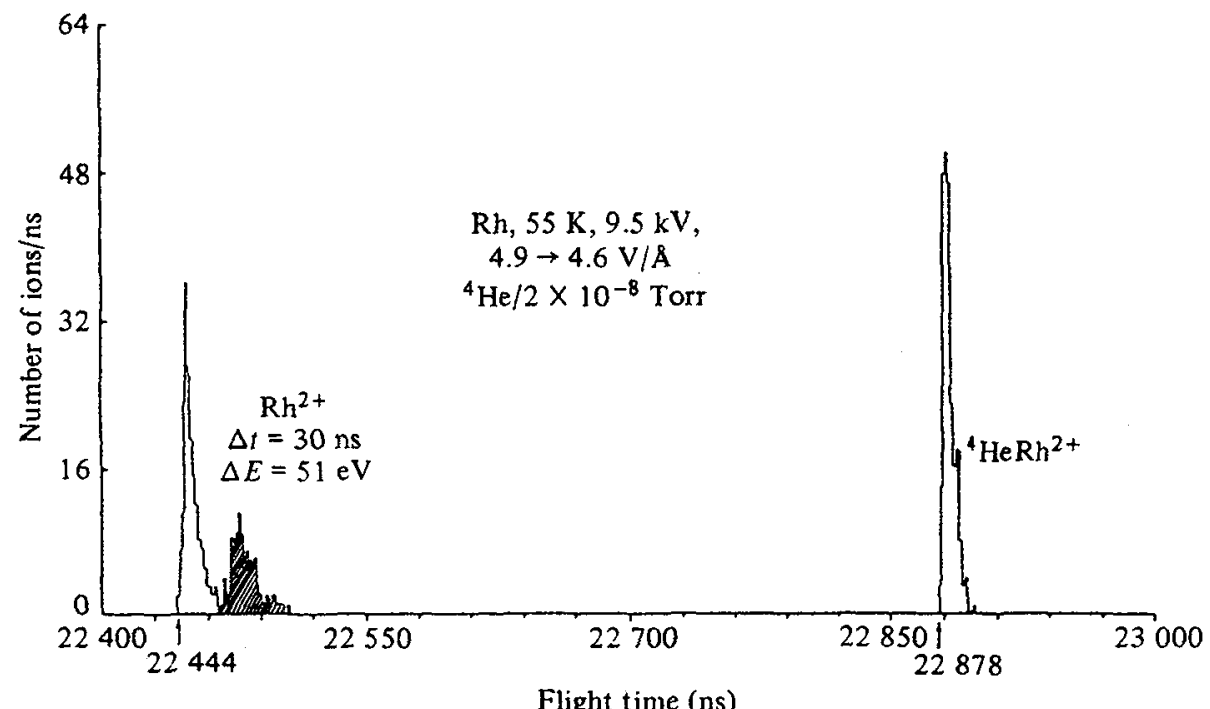

Flight time (ns)

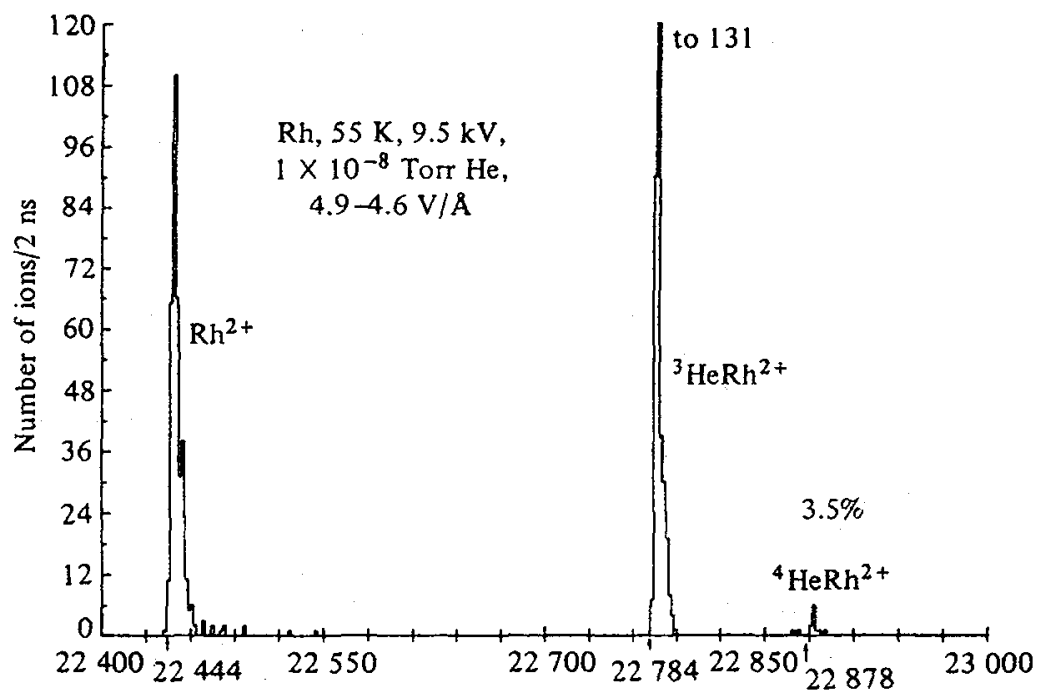

Flight time (ns)

Fig. 7 Mass lines in laser stimulated field evaporation of $\mathrm{Rh}$ in ${ }^{4} \mathrm{He}$ and ${ }^{3} \mathrm{He}$. 


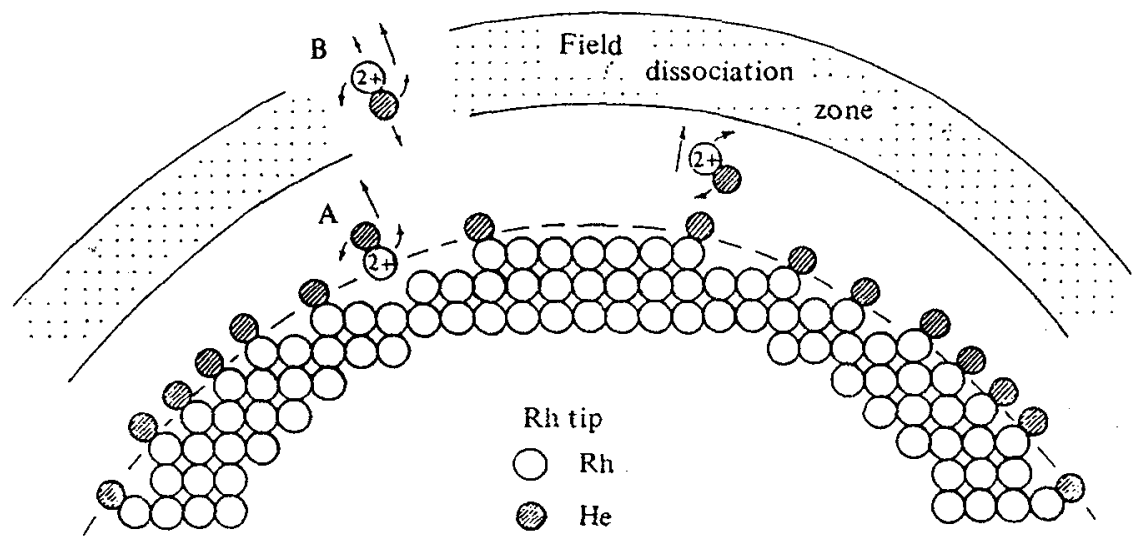

Fig. 8. A theoretical model for the observation based on field dissociation effect.

\section{SUMMARY}

Beside the above described experiments, using the great accuracy achievable in ion energy measurement of the ps pulsed-laser ToF atom-probe, we have also measured the critical ion energy deficits of many metals at low temperature. The binding energies of kink site atoms derived from these ion energy deficits agree with the cohesive energies of these metals to within $\pm 0.2 \mathrm{eV}$ [12]. Theoretically, the binding energy of kink site atoms should be equal to the cohesive energy. Our experiment confirms this equality for the first time. Ns pulsed laser technique has been successfully applied to heat the tip to induce motion of surface atoms and atomic reconstruction of $P t$ and $\operatorname{Ir}(110)$ and (001) surfaces for studying the atomic steps responsible for the reconstruction with a time resolution of a few ns [13]. The missing row structure of the (1x2) Pt and Ir (110), the quasi-hexagonal atomic arrangement of the $\operatorname{Ir}(001) 1 \times 5$ structure and the complicated reconstruction of the Pt(001) have all been observed with atomic resolution. A ps pulsed-laser imaging atom-probe was developed to observe reaction intermediates at lattice steps, and a signal intensity oscillations of the intermediates in surface promoted chemical reactions [14]. Although we have also observed image intensity oscillations, this subject was not further pursued because of the difficulty of distinguishing the effect of the applied field from the intrinsic chemical effect. Our linear type pulsed-laser ToF atom-probe has been developed into a mass and energy analyzer of great accuracy and resolution with single ion detection sensitivity. Many interesting phenomena and subjects have been studied in great details. 
Due to the general shift of interest of the science community to more applied research, the activity of this kind of research has subsided in recent years. Many interesting problems remain to be studied, and this activity may be revitalized in the future. Also, due to the length limitation, no applications to materials science are presented here.

The author acknowledges G. L. Kellogg, T. J. Kinkus. S. B. McLane, Q. J. Gao, Y. Liou, J. Liu, C. F. Ai, W. Liu and others for their contributions to some of the works described in this article.

\section{References}

1. E. W. Müller, O. Nishikawa and S. B. McLane, unpublished. See also E. W. Müller and T. T. Tsong, "Field Ion Microscopy, Principles and Applications", Elsevier, New York, 1969, pp.127, 276-278.

2. a. T. T. Tsong, J. H. Block, M. Nagasaka, and B. Viswanathan, J. Chem. Phys. 67 (1977) 2039. b. S. Jaenicke, A. Ciszewski, W. Drachsel, U. Wigman, T. T. Tsong, J. Pitts, J. H. Block and D. Menzel, J. de Physique, Coll., C7 (1986) 343.

3. T. T. Tsong, Surface Sci. 70 (1978) 211.

4. G. L. Kellogg and T. T. Tsong, J. Appl. Phys. 51 (1980) 1184.

5. T. T. Tsong, S. B. McLane and T. J. Kinkus, Rev. Sci. Instrum. 53 (1982) 1442; T. T. Tsong, Y. Liou and S. B. McLane, Rev. Sci. Instrum. 55 (1984) 1246.

6. T. T. Tsong, J. Chem. Phys. 85 (1986) 639; Surface Sci. 177 (1986) 593.

7. T. T. Tsong, Appl. Phys. Lett. 45 (1984) 1149; Phys. Rev. B30 (1984) 1149.

8. L. A. Bloomfield, R. R. Freeman and W. L. Brown, Phys. Rev. Lett. 54 (1985) 2246.

9. K. Raghavachari, J. Chem. Phys. 87 (1987) 2191.

10. J. Liu and T. T. Tsong, Phys. Rev. B38 (1988) 8490.

11. T. T. Tsong, Phys. Rev. Lett. 55 (1985) 2826; T. T. Tsong and M. W. Cole, Phys. Rev. B35 (1987) 66; J. Liu, C. W. Wu and T. T. Tsong, Phys. Rev. B45 (1992) 3659.

12. J. Liu, C. W. Wu and T. T. Tsong, Phys. Rev. B43 (1991) 13703.

13. Q. J. Gao and T. T. Tsong, Phys. Rev. Lett. 57 (1986) 132; T. T. Tsong and Q. J. Gao, Phys. Rev. B35 (1987) 7764.

14. W. Liu, C. L. Bao, D. M. Ren and T. T. Tsong, Surface Sci. 180 (1987) 153; see also p. 306 of T. T. Tsong, Atom-Probe Field Ion Microscopy, Cambridge Univ. Press, New York (1990). 